\title{
ETNOGRAFÍA HISTÓRICA DE LA PROTESTA URBANA: LAS JORNADAS NACIONALES CONTRA LA DICTADURA, SANTIAGO DE CHILE, 1983-1986
}

\author{
Historical Ethnograph of Urban Protest: National Jornadas Against Dictadura, \\ Santiago de Chile, 1983-1986
}

\section{VIVIANA BRAV0*}

Fecha de recepción: 26 de enero de 2017 - Fecha de aprobación: 9 de mayo de 2017

\section{Resumen}

Este artículo se concentra en las formas de lucha protagonizadas por los sectores de oposición a la dictadura cívico-militar de Augusto Pinochet durante las llamadas Jornadas Nacionales de Protesta, desarrolladas durante los años 1983-1986. A través de documentos y fotografías, testimonios y prensa de la época, se propone realizar un ejercicio de etnografía histórica en la ciudad de Santiago con el objetivo de revelar los sentidos, las trayectorias históricas y los espacios de la protesta urbana, y su inscripción como forma de construcción política y de organización social. Un aspecto relevante será el despliegue callejero, los símbolos de la rebeldía, los espacio y las formas de confrontación y reapropiación que construyeron el denso proceso de politización durante el periodo de estudio.

Palabras clave: protestas; dictadura militar; formas de lucha; neoliberalismo; Santiago.

\section{Abstract}

This article focuses on the forms of struggle starring the opposition sectors to the Augusto Pinochet civic-military dictatorship, during the so-called National Protest Days, developed during the years 1983-1986. Through documents and photographs, testimonies and press of the time, it is proposed to carry out an exercise in historical ethnography in the city of Santiago, with the aim of revealing the senses, historical trajectories and spaces of social protest, and its inscription as form of political construction and social organization. A relevant aspect will be the street deployment, the symbols of rebellion, the spaces and forms of confrontation and reappropriation, which built the dense process of politicization during the study period.

Keywords: protests; dictatorship; forms of struggle; neoliberalism; Santiago.

\footnotetext{
* Dra. en Estudios Latinoamericanos. Académica, Escuela de Historia, Universidad Academia de Humanismo Cristiano, Santiago de Chile. Correo-e: vivianabravo@gmail.com
} 
Todo lo que referimos aquí lenta y sucesivamente se verificaba a un tiempo en todos los puntos de la ciudad, en medio de un inmenso tumulto, como una multitud de relámpagos a un solo trueno.

Los Miserables, Víctor Hugo.

\section{Introducción}

Entre los años 1973 y 1990, Chile vivió bajo la dictadura cívico-militar del general Augusto Pinochet. Durante esos diecisiete años se implementaron diversas transformaciones estructurales que transformaron la relación estatal chilena construida a lo largo del siglo XX. El objetivo más apremiante, trazado por la declaración de principios de las Fuerzas Armadas y de Orden, fue despolitizar la sociedad chilena desmantelando sus organizaciones de base ${ }^{1}$. Se trataba, en definitiva, de destruir una trayectoria de organización y lucha. Como segundo paso, se propusieron transformar radicalmente lo que consideraban "la nociva cultura del reparto estatal" mediante un proceso de privatizaciones y el traspaso de responsabilidades sociales y recursos públicos a manos privadas. Ello fue acompañado por el cierre de oficinas públicas, despidos masivos de sus funcionarios y una disminución del gasto fiscal. Tal como ha apuntado el sociólogo Tomás Moulian, fueron puestos en marcha diversos dispositivos tendientes a materializar el nuevo proyecto societal ideado por la derecha y los militares. Como primera medida, estos sectores políticos recurrieron al poder-terror:

Poder para reprimir y para inmovilizar, pero también para conformar las mentes a través del saber, de un saber. De éste fluyen interpretaciones, ideas-fuerzas que explican y orientan la acción, pero también una normatividad, una capacidad creadora de normas, de prescripciones que se transforman en derecho, en poder-derecho, por tanto en "poder-hacer" (Moulian, 1997, p. 72).

Se estima que durante la dictadura fueron ejecutadas 3.179 personas, más de la mitad de ellas durante los primeros meses del golpe de Estado. Durante ese tiempo, más de 18 mil personas sufrieron torturas en manos de militares y fuerzas policiales adiestradas en técnicas antisubversivas, entre otros apremios ${ }^{2}$. De esta manera, clausurando el espacio para el disenso y la organización colectiva, se implementó el modelo socioeconómico que en los años siguientes le estaría reservado al resto de América Latina. Como es sabido, el proceso de reconfiguración del capital, que posteriormente conoceríamos como neoliberalismo, implicó cambios radicales en la política laboral, la seguridad social, la educación, la salud, la descentralización regional, la agricultura, el aparato judicial, entre otros (Gárate, 2012; Foxley, 1998; Montero, 1997; Meller, 1996). Los mayores costos del nuevo modelo de acumulación recayeron sobre los trabajadores y los sectores más desposeídos:

Junto a la conformación y crecimiento de conglomerados financieros, desarrollo del comercio y una concentración de la riqueza que permitió a los sectores privilegiados sostener altas tasas de consumo, todo el periodo estuvo acompañado por un importante deterioro de los salarios reales, cifras históricas de desempleo, aumento de la pobreza y desigualdades sociales, más aún durante las dos graves crisis de 1974-1975 y 1982-1983 (Bravo, 2012, p. 88).

No obstante, ante el cuadro que reseñamos la sociedad chilena no permaneció impasible. Fue un 11 de mayo de 1983 cuando las Jornadas Nacionales de Protesta irrumpieron en el espacio público y sorprendieron a una sociedad 
mantenida durante diez años bajo "toque de queda"3, allanamientos y detenciones, relegaciones y censura informativa. Así, diez años después del golpe militar, gracias a la convocatoria realizada por la Central de Trabajadores del Cobre (CTC) ${ }^{4}$, a la que adhirieron diversas organizaciones políticas y sociales, se desarrollaría un ciclo de rebelión popular que, con distintos ritmos y etapas, se mantuvo hasta prácticamente finalizar el régimen (Bravo, 2017; Delamaza \& Garcés, 1985).

Pero este proceso, que algunos llamaron "el despertar de las mayorías silenciosas", no nació espontáneamente de un día para otro. A pesar del aparente silencio y disciplinamiento, diversos hilos que configuran lo social construyeron un proceso de resistencia subterráneo y sigiloso, activado desde el mismo golpe de Estado. Buscar y dar refugio, intentar retomar lazos orgánicos, organizar o asistir a reuniones clandestinas, dar a conocer lo que sucedía en los territorios, un pequeño rayado en la pared o una protesta fugaz en una esquina transcurrida eran acciones que la oposición a la dictadura emprendió tempranamente. Esos pasos anónimos formaban parte de una historia proscrita, una historia de organización y lucha, un ethos colectivo construido y rearmado en una larga travesía para frenar los embates del capital, que es el que conforma la densa trayectoria de la protesta social chilena y que difícilmente podía desaparecer por decreto (Bravo, 2016, 2017).

En ese sentido, nuestra primera tesis sostiene que las protestas contra la dictadura fueron herederas de un ciclo más largo de lucha social. En la pelea por el salario, el trabajo digno, la lucha por educación, tierra y vivienda, los sectores populares y la clase trabajadora obtuvieron impor- tantes conquistas colectivas y lograron poco a poco -con altos y bajos- convertirse en interlocutores válidos ante la clase dirigente y protagonistas activos dentro del cuadro político nacional. La síntesis del largo camino de esa relación estatal fue el triunfo del proyecto de la Unidad Popular y la voluntad política de intervenir en todas las áreas para reestructurar el proceso económico en favor de la clase trabajadora y sus demandas históricas, materializada en la elección del socialista Salvador Allende en 1970.

Como segundo eje de análisis, sin desconocer el aporte regional, cuya historia aún merece mayor atención historiográfica, sostenemos que en el proceso que referimos, la ciudad de Santiago, capital del país, fue un escenario privilegiado y en él nos concentraremos. Los trabajadores, las trabajadoras y sus familias recorrieron la urbe, salieron de ella o ingresaron pacífica, solemne o agresivamente, y construyeron activamente una ciudad de masas en que la política fue parte fundamental de sus sentidos y ocupaciones. Multitudinarias marchas, concentraciones, romerías, represiones y rebeliones se realizaron en determinadas esquinas, pasajes y avenidas (De Ramón, 2007), cerca del poder burocrático, unas veces, o en la intimidad del barrio, en otras. En ese andar y protestar, conformaron trayectorias que alteraron o rompieron el tiempo de la reproducción de la vida (De Certeau, 1996). Se trata de sedimentaciones históricas que entrelazan las complicidades de la rebeldía y se despliegan hasta la actualidad cuando nuevos movimientos sociales y organizaciones políticas irrumpen en sus calles. Ni en forma lineal o predecible, en ocasiones los pasos pretéritos -en palabras de Walter Benjamin (2005)- destellan "como un rayo que ilumina el presente desde atrás". 
Por tanto, la complicidad con luchas y organizaciones de antaño es una referencia que debemos tener presente al intentar escuchar las voces de quienes opusieron resistencia durante las jornadas de protesta que aquí visitaremos. Acercarnos a estas manifestaciones dentro de su sedimentación histórica nos permite pensar en términos de cultura política e interrogarnos sobre la capacidad de la movilización social para hacer circular y transmitir la historia, tanto en la memoria viva de los participantes como en la memoria histórica de las organizaciones (Fillieule y Tartakowsk, 2015, p. 39; Tilly, 2008).

Durante las jornadas de protesta de la década de 1980, un movimiento policlasista y transversal en términos generacionales proponía que cada quien se manifestase según sus posibilidades. Ello nos permite observar la articulación de experiencias y formas de lucha ya utilizadas en otros momentos históricos y cómo se entrelazan con nuevas propuestas de movilización que resignificaron esos repertorios. De esta manera, formas de lucha recurrentes, como no asistir a clases, ausentarse del trabajo o trabajar más lento, tocar las bocinas, participar de los actos locales o sumarse al toque de cacerolas a una hora previamente convenida, se realizaron en conjunto con reuniones públicas masivas: pliegos, petitorios, concentraciones dirigidas por agrupaciones sindicales o partidos políticos, con marchas, ollas comunes, murales colectivos, actos musicales, etc. y convergieron con acciones provenientes de otra tradición de protesta social más cercana a la "revuelta" o la "acción directa" y que se visualizaron en el levantamiento de barricadas, fogatas, saqueos y enfrentamientos de carácter más frontal contra los símbolos de la dictadura o del poder. Todos estos elementos conforman la trayectoria histórica de la protesta social en Chile (Bravo, 2017).
Quizás debido a esa polifonía es que el significado de las protestas ha sido tan difícil de desentrañar: momento de la política agitativa; expresión de necesidades y aspiraciones colectivas; coordinación de prácticas populares diversificadas. Rabia, esperanzas, límites, sueños. Un campo amplio de la experiencia humana, colectiva. Por ello, en términos metodológicos, para comprender esa experiencia proponemos aquí un ejercicio de lo que llamaríamos historia a ras de suelo, o mejor aún, etnografía histórica. Proponemos escuchar las voces, indagar en los detalles, rastrear las huellas, los sonidos, las marcas que contienen nuestras fuentes: los relatos orales y los documentos, las fotografías y los diarios viejos, albergados principalmente en el Archivo Documental de la Vicaría de la Solidaridad, al que tanto debe esta investigación. Echarse a andar por las calles, las curvaturas del espacio, los muros; escuchar los mensajes que contuvieron las consignas, los panfletos, los rayados; lo que dijeron o callaron las piedras, las barricadas, el fuego. Aquí proponemos indagar en los símbolos que inscriben a las manifestaciones de protesta como una forma de construcción política y analizar su capacidad para convocar y organizar desde la lucha callejera a la sociedad y transformar los lugares en espacios, ya que como señalan Fillieule y Tartakowsky, un movimiento popular siempre parece condicionar la producción de un espacio y asociarlo a una historia (2015). Indisociables son, entonces, las formas y las expresiones de la protesta, los espacios de politización que conforman y los pasos que las y los moldean. Todas estas señales nos ayudarán a comprender la experiencia de vivir y resistir en dictadura. 
II

\section{El ruido}

Cuando una ciudad se transforma, se disciplina o se subvierte, los sonidos cambian. Por eso es que después del golpe militar del 11 de septiembre de 1973 y el bombardeo a la Moneda, muchos testimonios señalan que en Santiago se hizo silencio. Que después del bullicio, las consignas y las marchas, después de las disputas callejeras, de hablar alto, de la euforia, de discutir, votar en asambleas, de proponer consignas y cantar un himno militante a viva voz, vino un inquietante acallamiento. Entonces se escucharon los bandos militares, las botas de los soldados, las órdenes y ordenamientos. Las puertas y ventanas se cerraron, la política se refugió al interior, en pequeños espacios de solidaridad y confianza. Vino el tiempo de esconder identidades y enterrar libros comprometedores. EI momento de resistir por medio del pequeño formato clandestino, de los mensajes cifrados y los murmullos; de socializar en la intimidad de las redes familiares y vecinales.

Por eso, muchas y muchos tuvieron la sensación de que "las cosas comenzaban a cambiar" cuando en la tarde del 11 de mayo de 1983 , puntualmente a las 20 horas, el ruido de cientos de cacerolas, sartenes y rejas rompieron el disciplinamiento sonoro impuesto por los militares, marcando el inicio de una nueva etapa en la experiencia de resistir contra la dictadura. $\mathrm{Si}$ bien durante la mañana de esa primera Jornada Nacional de Protesta se escucharon aplausos, pifias y consignas, como el " $Y$ va a caer", verdadero mantra de la oposición, en las calles Ahumada, Estado, Huérfanos y Morandé del centro de Santiago, o en el Palacio de Tribunales, donde estudiantes de leyes protestaron, lo más llamativo fue que -tal como había propuesto la convocatoria de la CTC- el sonido de las cacerolas se esparció como una sola voz en la ciudad. Muchos supieron, al fin, reconocerse como uno más en esa multitud de percusiones.

Alejandro Correa, entonces dirigente estudiantil de las Juventudes Comunista (JJCC), nos relata que al caer la tarde de ese 11 de mayo, después de la ajetreada mañana de protestas y represiones, se encontraba junto a otros dirigentes evaluando la jornada, cuando les sorprendió un sonido que se filtraba por las ventanas:

\begin{abstract}
Estábamos escribiendo, sacando cuentas, qué se yo, y de repente el Yerko Ljubetic, que estaba ahí, que era dirigente demócrata-cristiano dice: "oye, escucha", abre las ventanas y se sienten los cacerolazos. Fue muy emocionante y tuvimos, y tuve personalmente, la sensación que ya no éramos los mismos, que por fin se habían masificado las cosas, o sea, durante mucho tiempo nosotros tuvimos la sensación que nosotros estábamos ahí, bregábamos, bregábamos y bregábamos y que no nos íbamos a rendir, pero también tenía un poco la sensación de estar solo, pero ahí cambió la situación (Alejandro Correa, 23 septiembre 2010).
\end{abstract}

En otro punto de la ciudad se encontraba Raúl Canales, militante del Movimiento de Acción Popular Unitaria (MAPU) y dirigente poblacional de La Pintana. Nos cuenta lo que protagonizó en su barrio:

El 11 de mayo del 83 andaba en la calle yo con mi señora, los dos solos. Mi mamá tenía una tapa de tambor, de estas de 200 litros de aceite, y con un palito salí, agarré la tapa y salí con mi señora, a la mitad de la calle, golpeando, golpeando y me paseé golpeando como dos cuadras, y después me devolvía, y en la vuelta ya traía como 20 tipos atrás, y recorrimos para el otro lado y cuando pasábamos íbamos los mismos 20 pero cuando volvíamos ya era una cuestión de unas 300, o 400 personas debemos haber juntado. Fue la primera vez que se salió a la calle, me acuerdo, partí como espontáneamente, no que fue pensado (Raúl Canales, 7 julio 2010). 
El golpeteo de cacerolas es una forma de protesta de data más antigua en la historia chilena. Por ejemplo, en 1947 la utilizaron las mujeres del carbón, las esposas, las madres y las hijas de aquellos orgullosos y rebeldes mineros sancionados durante el gobierno de Gabriel González Videla por oponerse a sus políticas antiobreras (Pavilack, 2011). Imitando su gesto, las mujeres de clase alta hicieron sonar las cacerolas en contra del gobierno de Salvador Allende, pero en verdad repetían una forma de protesta gestada desde abajo. Casi diez años después, el caceroleo recuperaba su impronta popular, resonando desde los patios de las casas y, cada vez con más frecuencia, desde grupos congregados en pasajes 0 esquinas poblacionales.

El historiador Manuel Loyola, militante del Partido Comunista (PC), coincide con lo significativo que fue la sonajera de las cacerolas a la hora de aunar los ánimos de la rebeldía durante la dictadura:

A lo que más se adhirió fue al caceroleo, la sonajera en la noche era espectacular, del caceroleo, o sea, todo Santiago caceroleado y otros golpeaban, qué se yo, postes metálicos, tocaban bocinas, yo creo que el ruido fue el gran elemento aglutinador, el lenguaje del ruido, como que identificó, es como una especie de código lingüístico (Manuel Loyola, 24 septiembre 2010).

Un momento especial en la disputa sonora que referimos fue el caceroleo que provino desde las poblaciones periféricas de Santiago y que espontáneamente acalló la cadena nacional desde la que el general Augusto Pinochet se dirigió al país para despedir el agitado año 1983. En la periferia no lo habían programado, simplemente fue la forma de expresar el rechazo a un dictador y sus palabras.
De esta manera, las cacerolas marcaron el tiempo de la protesta, de las fogatas, de las proclamas en contra de un sistema opresivo y autoritario. Aspasia, joven universitaria de aquellos años, vivía en Quinta Normal, un barrio de clase media de Santiago y el sonido de las cacerolas le ayudó a extender puentes con sus vecinos:

Esa sensación emocional de esta historia, de sentirte
parte, a pesar de que en mi cuadra, por ejemplo, un
barrio antiguo, yo creo que éramos los únicos, yo y mi
mami, pero nos sentíamos acompañadas porque en la
cuadra siguiente había alguien que estaba golpeando
y se escuchaba, tú hacías un sonido y te respondían,
entonces la emocionalidad de eso era súper fuerte, muy,
muy fuerte... o escuchabas un balazo supongo a lo lejos
o el famoso helicóptero (Aspasia, 23 septiembre 2010).

En efecto, los sonidos del orden militar no desaparecieron, pero se les disputó el espacio sonoro de despliegue. De hecho, el ruido de los helicópteros, las sirenas, los gritos intimidatorios de advertencia y los balazos siguieron siendo parte indisociable de la atmósfera acústica. Por ejemplo, en la Tercera Jornada, realizada en agosto de 1983, Manuel Loyola, y tantos otros, no pudieron conciliar el sueño:

La cantidad de balazos esa noche fue impresionante, conocía a personas que fueron muertas esa noche. Fueron muertas por balas de carabineros. Entonces, sentir que un conocido tuyo llegó a morir de un balazo en el corazón... Hubo jornadas muy duras, muy fuertes, una actividad represiva muy fuerte, donde los pacos disparaban a las casas. El amigo mío que murió protestando, y estaba ahí, en la esquina de su casa, haciendo un corte con neumáticos, una barricada, y cuando ve a los pacos, sale arrancando, entra a su casa, creyéndose que estaba a salvo, cierra la puerta y se pone detrás de la puerta, a esperar que pasen los pacos. Los pacos se detienen en la barricada y empiezan a tirar balazos a varias casas, con la mala suerte que un balazo atravesó la puerta, y le llegó justo al corazón, por la espalda (Manuel Loyola, 24 septiembre 2010). 
Aunque el horror no daba tregua y tras las jornadas se registraban muertos, heridos $y$ detenidos, el paso al frente que había dado la oposición levantando la voz continuó durante las 12 jornadas nacionales que se realizaron entre 1983 y $1984^{5}$. Junto a las cacerolas se escuchaban consignas, bromas e insultos. También otros sonidos, como los silbatos que utilizaban grupos de mujeres movilizadas, para congregarse. Al respecto nos cuenta Pancha, militante comunista: "Los pitos fueron nuestras armas principales, nos comunicábamos, nos parábamos en la esquina, nos reagrupábamos, si nos dividían, arrancábamos por todos lados y después métale pito, nos volvíamos a agrupar". (Pancha, 20 septiembre 2010).

Otro sonido inolvidable para quienes experimentaron estos años de lucha contra la dictadura fue la cortina de Radio Cooperativa, escuchada por toda una generación en días y noches de protesta, muchas veces con radio a pilas y a la luz de una vela, debido a los cortes de luz. Para Aspasia, la sensación que le provocaba ese sonido la acompaña hasta la actualidad:

\footnotetext{
He conversado con gente de mi edad y gente mayor que yo, inclusive en el trabajo, que a mí me pone nerviosa la cortina de esa radio: "la Radio Cooperativa está llamando". Me pone tensa, el tacatacatacatacatacatacataca... en este minuto, no, o sea, esa payasá apretaba la guata al sentir eso, ponte a las siete de la noche que empezaba el "Radio Cooperativa está
}

llamando" y eso significaba que algo estaba pasando, que a alguien habían matado, que estaban deteniendo gente. Entonces, yo escucho eso ahora, y me aprieta la guata, yo pensé que era una estupidez mía, pero hay mucha gente que tiene esa misma sensación porque era la única posibilidad de saber lo que estaba pasando alrededor, aparte del sonido, era la radio (Aspasia, 23 septiembre 2010).

También la música de protesta acompañó los ánimos de estos tiempos. Una generación configuró su identidad política cantando en parroquias, centros culturales universitarios y peñas clandestinas. Escuchando una y otra vez los cassettes regrabados que circulaban de mano en mano o en las voces de cantores de micros que se atrevían a recuperar y difundir cotidianamente canciones de rebeldía. La discografía de Silvio Rodríguez, Víctor Jara y del contingente del Canto Nuevo, entre muchos otros, resonaba junto a melodías nortinas como "El negro José" de Illapu y sonidos más rockeros, cumbiancheros, fusionados o alternativos, como el grupo Los Prisioneros con su legendaria "La Voz de los 80"; Transporte Urbano, con "La cumbia del paro" o "El muchacho"; Sol y Lluvia, con "Adiós General", además de grupos como Congreso y De Kiruza. Salvo algunas piezas de corte instrumental, lo importante era que se trataba de música en castellano, con contenido o "con letra", como se decía en la época. 
Foto 1. Marcha por el centro de Santiago, septiembre 1984.

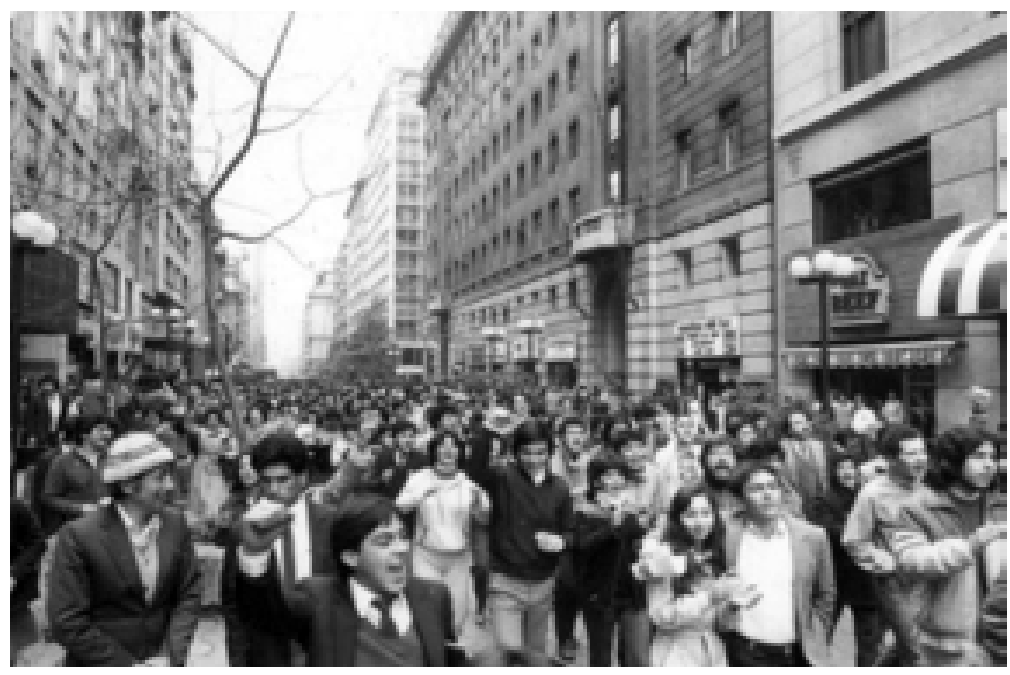

Fuente: Archivo Documental Vicaría de la Solidaridad.

Si algo inquieta al orden es el ruido, la música, las voces disidentes, antípodas de su régimen sonoro. Un régimen que requería hablar fuerte y silenciar la diferencia. Esa grieta acústica fue la principal característica del paso al frente que siguió en el comportamiento rebelde. Fue así como se generó una vigorosa polifonía que agitó las pasiones de la ciudad y el clima de sensibilidad en tiempos de protesta.

\section{El día}

No da lo mismo protestar de día o de noche. Así lo saben los protagonistas de estos tiempos. Distintas formas de lucha, distintas ocupaciones, trayectorias, roles. Lo sabía cualquier joven estudiante de la periferia de Santiago. La protesta tiene tiempos claramente diferenciados. También lo sabía un trabajador que debía cruzar la ciudad para llegar a su casa: ¿quiénes protestaban de día?, ¿cómo protestaban?, ¿en qué espacios?
Sin duda, el día era de las y los estudiantes, secundarios y universitarios. Desde temprano, por ejemplo, grupos de jóvenes se congregaban en las cercanías de la Facultad de Derecho de la Universidad de Chile o en el puente Pío Nono para detener el tránsito en horas claves de circulación en un punto neurálgico para el tráfico santiaguino. Otros tantos se reunían al interior de sus universidades, normalmente en paro de actividades. Después de realizar un acto cultural de mediodía, en que resonaban las guitarras y las flautas, después de pronunciar y escuchar discursos que terminaban con un "a la calle compañeros", piquetes de jóvenes salían a cortar las calles adyacentes. Así ocurría en los contornos del ex Pedagógico y en diversas facultades de la Universidad de Chile, en el campus oriente de la Universidad Católica y en la Universidad de Santiago. En ocasiones, algunos estudiantes de leyes alborotaban los ánimos al interior del Palacio de Tribunales, rompiendo protocolos y silencios. 
Los estudiantes secundarios eran los protagonistas a la hora de alborotar el centro de Santiago. Muchachos y muchachas cargando cuadernos, mochilas, piedras y hondas se congregaban en la Biblioteca Nacional e intentaban -infructuosamente- marchar en bloque por la Alameda. Ya sabían que los dispersarían, pero también sabían dónde y cómo reagruparse. No importaban ni las lacrimógenas ni los carros lanza-agua que les empapaban los uniformes. Conocedores de los recovecos de la ciudad, sabían moverse y escabullirse, e intervenir el tiempo de los burócratas con barricadas levantadas en el cuadrante político-administrativo de la ciudad.

Así fue ese tiempo de adrenalina para Juan Alfaro, estudiante de enseñanza media, dirigente del Liceo de Aplicación, detenido 14 veces durante la dictadura:

Marchaban los secundarios y no quedaba banco bueno, si nos salíamos con todo. Ventanal que veías te lo echabas, de un banco, de una institución financiera, de gobierno, era violento el asunto. Los pacos llegaban tirando balas, balines, granadas lacrimó- genas, te sacaban la mugre, el apaleo te lo llevabas de seguro, pero así era, y cuando tú le tenías que dar, no había posibilidad de solo recibir. El estudiante secundario tenía esa experiencia, la construiste en la lucha callejera, conocía el espacio, es su espacio natural, el del liceo (Juan Alfaro, 8 octubre 2010).

Y continúa dando cuenta de los niveles de organización alcanzado por los secundarios, con miras a generar un hecho político, un pronunciamiento explícito en contra de un sistema educacional que reproducía en las aulas las consecuencias de una estructura social, un sistema económico y la atmósfera de autoritarismo político que experimentaba el país:

\begin{abstract}
Nosotros teníamos un plan de copamiento pero que "te lo encargo". Con distintas dimensiones, por ejemplo, a nivel de barricadas y de puntos para cortar el tránsito, el tiempo que demoraba la repre en llegar, por donde llegaban, todo eso estaba estudiado. Lo nuestro era la cosa en el centro, era copar el centro, hacer noticia, luchar en el centro, mostrar la lucha de alguna manera, levantar la moral del pueblo, que vean que los estudiantes están en la calle, que la gente está descontenta, sembrar eso (Juan Alfaro, 8 octubre 2010).
\end{abstract}

Foto 2. Protesta de estudiantes secundarios, centro de Santiago, octubre 1985.

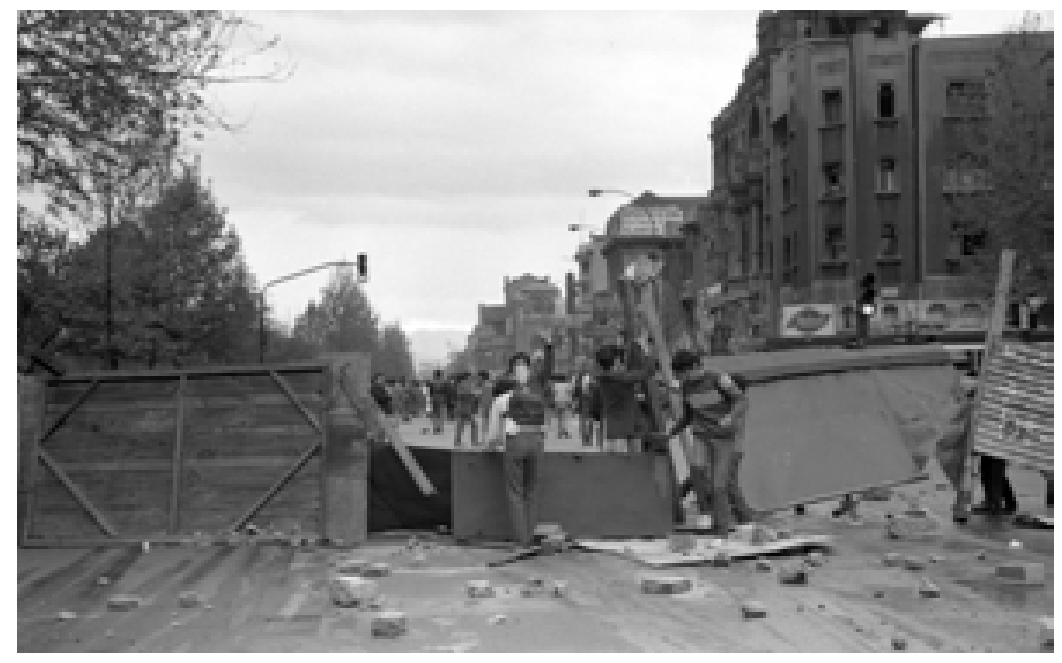

Archivo Documental Vicaría de la Solidaridad. 
Durante la mañana de una jornada de protesta, el concurrido paseo Ahumada ubicado en el centro de Santiago no parecía muy distinto al de un día común. Oficinistas, vendedores y peatones circulaban apresurados como de costumbre. Pero había ciertas señales y presencias que marcaban la diferencia y que solo un observador atento podía constatar: algunos puestos de periódicos con sus cortinas abajo, algunos rostros que se reconocían y saludaban a lo lejos y comenzaban a congregarse. Entonces una señal auditiva (una consigna) o visual (panfletos volando) marcaba la ruptura de la cotidianidad. Muchas mujeres militantes, trabajadores con corbata, dirigentes sindicales y políticos terminaban de reunirse, cantaban y aplaudían beneficiados por la fuerza acústica que permite la disposición de los viejos edificios del centro santiaguino. Generalmente, el contingente comenzaba una marcha hacia la Plaza de Armas, o lo intentaban al menos, ya que piquetes de carabineros con sus perros policiales hacían lo posible por disuadirles. No obstante, muchos alternaban sus rutas para congregarse finalmente afuera de la Catedral o muy cerca del edificio que ocupaba la Vicaría de la Solidaridad y que ofrecía algún tipo de refugio. Era en ese punto donde acostumbraban reunirse los "líderes nacionales" o miembros más reconocidos de los partidos políticos de la oposición, cantando la canción nacional o realizando un discurso frente a las atentas cámaras de la prensa nacional e internacional, interesadas en seguir los sucesos. No está de más agregar que muy pocas veces lograban terminar sus cantos pues eran alcanzados por carros lanza-agua y agredidos por carabineros de pie con sus bastones de servicio en mano, que reprimían, muchas veces, sin distinguir entre reporteros o fotógrafos y manifestantes.

\section{La noche}

Al caer la tarde se levantaba otro telón en los diversos actos que constituían una jornada de protesta. No eran pocos los trabajadores que pedían salir antes y apuraban el tranco para llegar a sus casas. Sabían que escasearía la locomoción, que la luz podría estar cortada y preferían resguardarse por prudencia. Pasarían a comprar velas y pilas, se refugiarían en sus comedores y a las 20 horas tocarían las cacerolas. Pero otros querían llegar pronto para participar en la organización callejera de las barricadas. Porque la noche era de las poblaciones, en especial las periféricas que circundan la ciudad de Santiago. En esos espacios se vivenciaban los mayores niveles de enfrentamientos (hacia afuera), pero también de solidaridad (hacia adentro).

El siguiente relato de Miguel, joven poblador entrevistado por Patricia Politzer durante la dictadura y plasmado en su libro La ira de Pedro y los otros, nos transporta a una de las jornadas de protesta, con sus diversas dimensiones y tensiones:

\begin{abstract}
Eran las ocho de la noche, se prendieron unos forros, los cabros se pusieron a golpear la reja para que se armara un caceroleo, algunos se empezaron a columpiar y, de repente, los fierros cedieron y se cayó un pedazo. Nos entusiasmamos y seguimos sacándola para usarla de barricada. En eso estábamos cuando llegaron los milicos en tanquetas, disparando al tiro. Todos arrancamos y la gente dejaba las puertas de sus casas abiertas para que pudiéramos meternos. Había protesta todas las noches. Nos juntábamos a cortar la luz con unas cadenas y, cuando aparecían milicos a cuidar el metro, les tirábamos las molotov (Politzer, 1988 , p. 102).
\end{abstract}

Puesto que la oscuridad permite el anonimato, en Santiago la noche podía volverse muy oscura 
gracias a los apagones nacionales realizados desde fines de 1983 por el Frente Patriótico Manuel Rodríguez mediante la colocación coordinada de explosivos en torres de alta tensión. Pero los cortes de luz se debían también, en forma mayoritaria, a los llamados "cadenazos", es decir, lanzamientos de cadenas a los cables de energía eléctrica que cortaban la luz en las calles de los barrios, realizados principalmente por jóvenes militantes en sus espacios poblacionales. Y es que la oscuridad, según nos señalan, les permitía un mayor marco de tranquilidad para correr y escabullirse en caso de ser necesario. Se trataba de resguardar la intimidad, la tranquilidad necesaria para realizar rayados, lanzar piedras, acarrear pertrechos para las fogatas 0 congregarse en torno al fuego, incluso también para jugar a la pelota, reírse, apropiarse de la calle. Esto lo confirma el testimonio de Alejandro:

La noche, la oscuridad, el tirar los cadenazos para reventar los transformadores y el fuego provocó una situación de confianza en la gente y una catarsis, porque la dictadura no es una situación solamente que a ti no te dejen hacer determinada cosa, sino que tú sientes que te están castrando, o sea, te sientes indigno, te sientes enmierdado por decirlo así... y esa cuestión como que estallaba en las protestas (Alejandro Correa, 23 septiembre 2010).

Si en perspectiva puede parecer fácil, participar en una jornada era algo complejo que requería valor y que se reforzaba colectivamente, es decir, tenías la certeza de que no eras el o la única, que mucha gente arriesgaba su existencia. Se sabía y era una responsabilidad que impulsaba el compromiso, el ser parte de esos muchos que fueron heridos e incluso que murieron intentando gritar su protesta en las calles del país. El cantautor Francisco Villa, entonces militante de las JJCC, también lo experimentaba de esa forma:
Salía en las noches a hacer rayados, panfletear, a tirar miguelitos porque venía la protesta, a hacer los chapazos, que era ponerle un palo de fósforo con poxilina a los candados para que no se pudieran abrir los colegios al día siguiente o las industrias, las patrullas dando vueltas, entonces, digo, era después una cosa súper riesgosa. Yo las cuento en primera persona porque es lo que yo hacía, pero eso lo hacían otros también, yo era parte de un grupo (Francisco Villa, 21 octubre 2010).

Manuel Loyola, por su parte, da cuenta del trabajo de grupos militantes que fueron adquiriendo mayor capacidad operativa, como las unidades de combate de las JJCC y las milicias rodriguistas, que respondía al trabajo territorial del Frente Patriótico Manuel Rodríguez:

Con la caída de la noche, la protesta era protesta, ya no había vídeo que ver, ya era salir a tocar la cacerola, hacer la fogata, hacer la barricada, enfrentarse a los pacos, empezar a combatir, hacer cruces, llenar con miguelitos, liberar zonas, pretender atacar algún cuartel policial, atacar municipios con bombas molotov, tirándole paquetes de velas, explosiones. Ya los compañeros podían hacer asaltos, podían desarrajar panaderías, supermercados, sacaban las matracas, tiraban sus disparos y ahí podía haber un público más general que podía asistir a eso, podía aprovecharse incluso, hacían asaltos, saqueos y cosas de ese estilo (Manuel Loyola, 24 septiembre 2010).

La imaginación que acompañó el ánimo de rebelión creó un verdadero arsenal popular. Se trataba de sintonizar la creatividad con la necesidad de protección y ataque utilizando los materiales que se tenían a mano. Junto con las piedras, para impedir que circulara cualquier tipo de vehículos, pero especialmente los policiales, se confeccionaban en los talleres caseros los famosos miguelitos, clavo de tres puntas que se regaban en las calles preferentemente cercanas a los paraderos de micros, pero al no ser tan efectivo para 
los neumáticos más gruesos que demoraban más tiempo en quedar inservibles, se idearon distintas versiones de los llamados cacho'e cabra, que se enterraban durante la noche en el pavimento, de cara al tráfico con un filo perpendicular. Nos explica Raúl Canales:

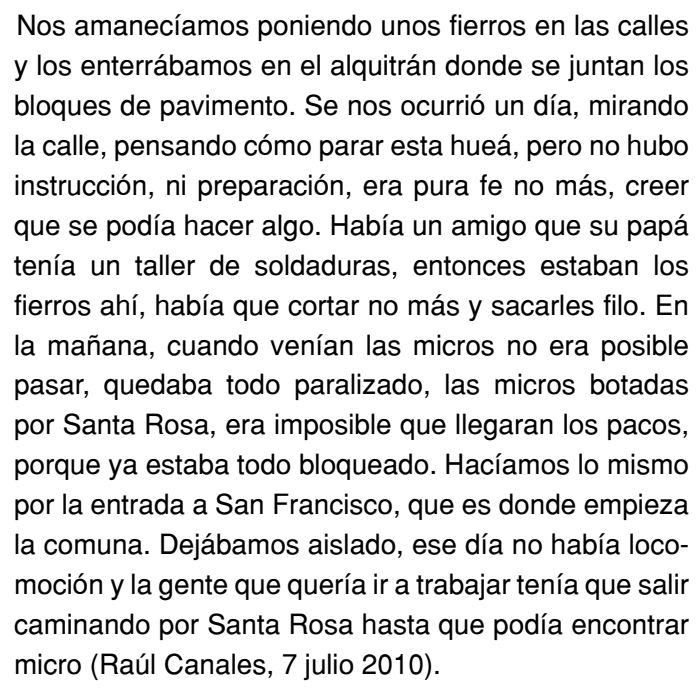

Fue en esas noches de protesta, muchas veces cerca de una barricada, cuando se congregó ese "despertar de las mayorías" con un nivel de coordinación y organización que cuestionó, o al menos puso en entre dicho, las apreciaciones sobre la supuesta despolitización de la sociedad chilena.

\section{El fuego}

Símbolo y advertencia casi al mismo tiempo, el fuego apareció en ese paso al frente que significó la protesta. Fue el elemento visual más presente, marcaba territorio, calentaba el frío y los temores, congregaba, alejaba a las bestias. El fuego característico del cinturón periférico santiaguino, de sus colegios y universidades en días y noches de lucha callejera, fue una trinchera, pero también un foco y un límite. El fuego, al igual que el ruido, comenzó al caer la tarde de la Primera Jornada de Protesta, cuando Santiago fue sorprendido por un cinturón de barricadas que destellaban en la periferia. Bajo su resplandor la noche de la protesta se convirtió en día.

"Yo asocio las protestas a cosas muy simples, como el fuego, barricadas, risas, hueveo y una actitud asociada a la pérdida del miedo", señala Claudio Pérez, entonces habitante de la población José María Caro y estudiante del Liceo de Aplicación (28 septiembre 2010). El fuego permitía crear una atmósfera de intimidad, demarcaba el territorio, ponía obstáculos al paso de las fuerzas represivas, y también calentaba las noches de ese frío otoño en que comenzaron las jornadas. Y si lo que sucedió esa noche a algunos manifestantes los tomó por sorpresa, para la Segunda Jornada de protesta, realizada un mes más tarde, organizaciones de pobladores y militantes de partidos políticos se prepararon para que la disposición a protestar no los encontrara desprevenidos y favorecer la multiplicación de las fogatas. En esas semanas, Alejandro Correa, como dirigente de la Comisión Chilena Pro-derechos Juveniles (CODEJU), se acercó a la Coordinadora Sur, para saber cuál podría ser la forma de apoyar y establecer una coordinación conjunta:

En esa reunión con las organizaciones sociales, los tipos ya estaban organizándose más, estaban haciendo acopio de neumáticos, gasolina, piedras, peñascos, ¡cuánta cuestión a ese nivel! El tema era impedir que las fuerzas represivas pudieran ingresar a las poblaciones para evitar muertes, entonces los tipos estaban diseñando cuáles eran las zonas en que iban a contener la represión y etc. La gente de la población de La Victoria empezaba a las 10 de la mañana a hacer trincheras, 
trincheras hondas, que ya no podían entrar los pacos, o sea, la gente empezó a desarrollar tempranamente el tema de la autodefensa a nivel de las poblaciones (Alejandro Correa, 23 septiembre 2010).

Esto lo confirma la señora Alicia Cáceres, dirigente social de la población La Victoria, testigo y protagonista del crecimiento de la organización durante las Jornadas Nacionales:

Al principio no éramos tantos, pero después era una masa inmensa, la gente cuando ocurría algo salía toda a la calle, aquí todos salían a hacerle frente a los milicos, a los pacos, se ponían barricadas, entonces no podían llegar tanto a la capilla. Una que no podían pasar y otra que de todos lados les empezaban a tirar piedras, a gritarles jasesinos! y qué se yo, iy barricadas por todos lados! Con esto del fuego no podían pasar, no podían apagarlas todas, en eso los cabros se iban al chancho... sacaban las... (risas) todavía hay veredas menos, iy acarreaban todo lo que encontraban viejo en su casa para hacer unas tremendas barricadas! (Alicia Cáceres, 6 julio 2010).

Como señalamos anteriormente, Patricia Politzer también intentó comprender los motivos que encendieron el fuego durante la dictadura y ofrecer una explicación de la participación social en las movilizaciones callejeras. La furia, para ella, fue un elemento clave. Nos relata:

Era enorme la rabia que tenía la Natalia [...] Ese es, quizás, el sentimiento común, el que los mueve y une a pesar de sus diferencias. Unos se dicen marxistas, otros cristianos, otros simplemente están ahí sin necesidad de definirse. Participan diligentes en toda acción de protesta, sin importarles mayormente quién convoca ni cuál es el objetivo inmediato. Son -por sobre cualquier calificación- activos militantes de la fogata (Politzer, 1988, p. 24).

Pero no era solo ira. Las barricadas fueron un espacio privilegiado para la socialización política. Risas, insultos ingeniosos, correr y esconderse para que no te atrapen entrañaba una forma lúdica de vivir la juventud que compartió esta generación y que engrosó las hojas de una nostálgica bitácora que hasta hoy reseñan sus protagonistas. Bitácora de la resistencia que abren de tanto en tanto para rememorar el anecdotario de aquellos tiempos de desobediencia contra el poder y de incendiar prácticas y órdenes impuestas en el fuego de una barricada. Pero no eran solo jóvenes. Sindicalistas con experiencia previa, como don Luis Fuentealba, encendieron y participaron en barricadas durante la dictadura. Para él, estar en la calle luchando era sinónimo de respetabilidad, ya que requería valor, compromiso, asumir ser parte de una lucha colectiva, tal como lo demostró el reconocido dirigente sindical democratacristiano, Manuel Bustos, tanto en la calle como en las asambleas:

Cuando tú miras a las personas con historia es muy distinto ver la gente que no tiene historia, como yo, poder hablar mal de Manuel Bustos, si Manuel Bustos estuvo conmigo enfrentando palos, golpes, de todo. Estuvo conmigo poniendo barricadas, encendiendo neumáticos, cuando todo el partido DC estaba contra la unidad con los comunistas, en plena dictadura (Luis Fuentealba, 14 octubre 2010).

El olor de la barricada se mezclaba con todo lo que componía el aroma de la protesta, el combustible que se derramaba junto a las molotov o con el que se encendían las hogueras y las mangas, esos rollos de aserrín y tela que cruzaban una calle o avenida de un extremo a otro y eran incendiados para impedir el paso de vehículos. Pero el olor a la protesta también traía el de las lacrimógenas. Era un olor represivo que incluso provocaba desmayos, vómitos $y$ ataques de angustia. Para mermarlo se 
acostumbraba portar pañuelos con amoniaco o pedazos de limón y sal, que aliviaban los síntomas y que los participantes precavidos guardaban en sus bolsillos y morrales.

Al día siguiente estudiantes y trabajadores que se desplazaban desde la mañana sentían ese olor a humo que emanaba desde las fogatas apagadas, hasta que escuadrones de trabajadores municipales eran enviados a limpiar el pavimento. Claudio Pérez, como muchos otros jóvenes, pasaba entre barricada y barricada para llegar a la escuela en la mañana:

Por eso me resulta imposible separar una historia de vida con las imágenes del fuego y del humo: llevaba el cuello, la cabeza, todos ahumados, con olor y humo de neumático... la nariz negra... y todos llegábamos así. Los restos de barricadas podían quedar días ahí. Quedaba todo el hollín y las micros pasaban sobre él (Claudio Pérez, 28 septiembre 2010).

Foto 3. Población La Victoria, octubre 1983.

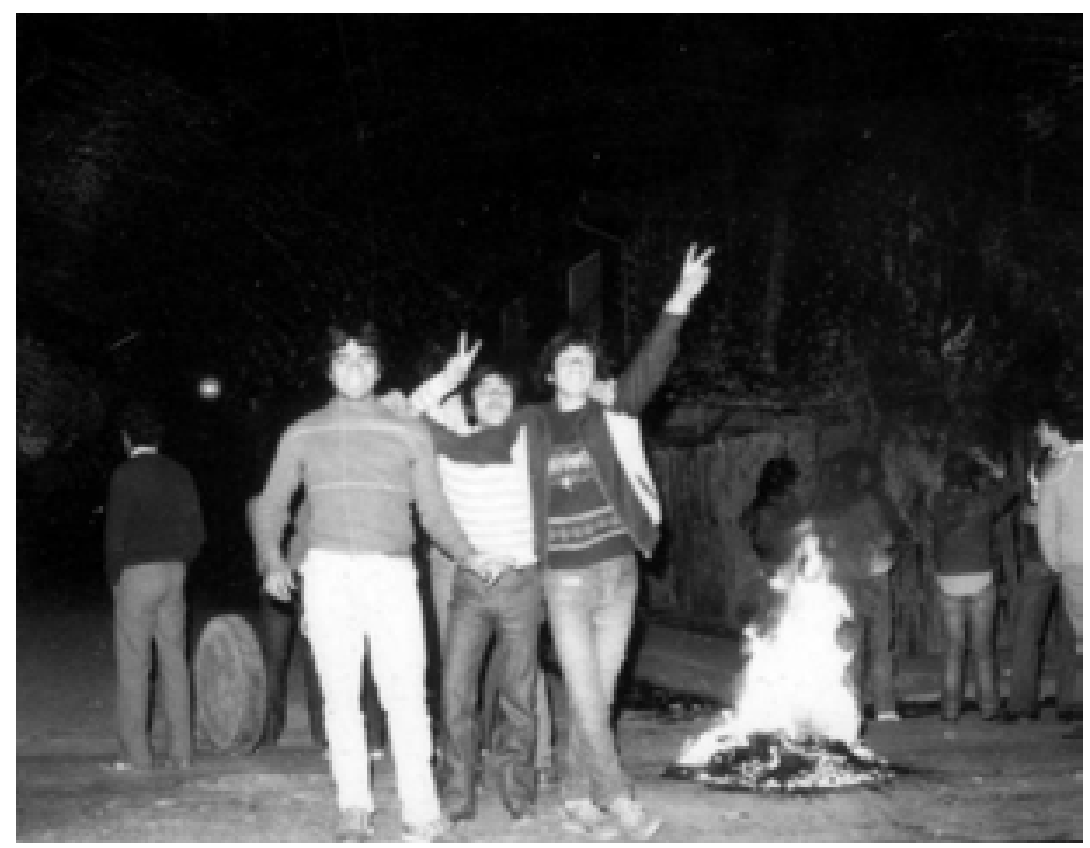

Archivo Documental Vicaría de la Solidaridad.

El fuego también estaba presente en otras formas de manifestación con alto grado simbólico, como era incinerar una figura que representaba a Augusto Pinochet. Previamente se desarrollaba una solemne representación en que el dictador era juzgado moralmente y casti- gado por un tribunal popular. Claudio participó en diversas réplicas de ese ajuste de cuentas, que él llama "la rutina del mono":

Siempre había alguien con los típicos carteles "que se vaya Pinochet" y con un mono que luego se quemaba, que era Pinocho. Siempre partía desde 
una de las calles principales de la José María Caro, luego marchaba hasta Albano, donde se quemaba y toda la gente aplaudía. Esa era la rutina del mono. En las concentraciones contra la dictadura siempre había monos quemados. Recuerdo que, en el Estadio Nacional, cuando jugaba la "U" u otros equipos, también circulaban los monos, alguien les escribía por ahí que era Pinocho, y circulaban de un lado a otro, alguien lo quemaba y lo tiraban. De hecho, algunas veces lo ahorcaban y el mono quedaba colgado (Claudio Pérez, 28 septiembre 2010).

Se trataba de un ritual que retomaba viejas tradiciones que recreaban y reactualizaban la animadversión del pueblo hacia un personaje que invariablemente terminaba ajusticiado por las llamas, lo que restauraba simbólicamente un sentido de justicia y valores ausentes. Como ha señalado el historiador británico E. P. Thompson (1997) para el caso inglés, se trata de prácticas políticas expresadas en la teatralidad repetitiva del escenario público y masivo de las calles y los mercados. De esta manera, en el rito poblacional santiaguino se leía previamente un manifiesto donde se detallaban una a una las acusaciones que constataban el crimen del apóstol traidor. El juicio popular era contundente: fuego para exorcizar el mal.

\section{Las piedras}

Fueron las piedras las armas más populares entre los pobres y los jóvenes. Primero en forma aislada, tímidamente, lanzadas por manos anónimas y escurridizas. Inscritas en la trayectoria de la protesta social chilena como defensa contra el despojo, la injusticia y la opresión, ciertamente habían sido lanzadas contra las fuerzas represivas en otros momentos de la historia de Chile y difícilmente podían desaparecer por un bando militar. La diferencia en esta coyuntura de la década de 1980 fue la persistencia, la obstinación, la repetición del acto rebelde que erróneamente algunos interpretaron como "monótono" o "rutinario" (Arriagada, 1998; Tironi, 1987; Valenzuela, 1984) ${ }^{6}$, quizás porque para ellos había perdido la cualidad de "sorpresa", pero para otros se consolidaba como una práctica cotidiana. Es precisamente esa normalización de la actividad rebelde lo que llama poderosamente la atención. Porque ello, hasta al menos el año 1987, fue aunado a otro elemento distintivo: la masividad y la transversalidad.

Fue tirando piedras que una generación se politizó y aprendió a defenderse. Tirar piedras requería adiestramiento, coordinación, una cuota de adrenalina y audacia. Conocer las calles, los intersticios, los muros y las rejas. Imposible saber quién fue ni dónde se tiró la primera piedra de protesta contra la dictadura. Pero hubo un antecedente inmediato, la Marcha del Hambre del 30 de agosto de 1982, que algunos, como Alejandro Correa, trazan como un hito inaugural:

En esa marcha se produce un cambio interesante. Nosotros, cuando íbamos a las marchas, la dinámica era la siguiente, se juntaba un lote de gente en una esquina y empezamos a aplaudir y de repente uno empezaba, iy va a caer!, y comenzaba a generarse un proceso, y cuando aparecían los pacos, es decir la policía, salíamos todos arrancando. Duraba dos minutos, tres minutos exactos, y eran los mismos 50 o 60 gallos, eran los mismos, siempre. Ahora, en esos procesos de la Marcha del Hambre, ocurrieron dos cosas interesantes: uno, la gente comenzó a perder el miedo ante la represión. En la marcha del 30 de agosto, por primera vez, la gente le hizo frente a la policía. Ahora, le hizo frente porque también había gente que iba preparada para hacerlo, o sea, llevaban piedras en los bolsillos, etc. Entonces atacan los carabineros y en vez de arrancar la gente se detiene y les tira piedras. Entonces se produce un desconcierto en ellos y la gallá adquiere confianza (Alejandro Correa, 23 septiembre 2010). 
Fueron piedras y no fusiles las armas más populares de la rebeldía, o más bien, eran piedras contra fusiles. Las piedras, eso sí, eran lanzadas por una multitud de manos. En ellas hay una posición política, que no es la del discurso o las letras, pero curiosamente, después de ellas $-\mathrm{y}$ en medio de ellas- las conversaciones y el reposicionamiento de los líderes nacionales pudo comenzar. Sí, las piedras sacaron palabras, pero por sí mismas también dijeron muchas cosas. Hablaban, por ejemplo, de la irrupción de los militares en las calles, de sus allanamientos y golpes. Hablaban también de recuerdos y sentimientos proscritos.

Cuando a Pedro le preguntaron en 1987 “¿cómo es hacer política hoy?” respondió sin vacilaciones: "Para el poblador de 20 años hacer política: jes agarrar a piedrazos a los pacos!" (Politzer, 1988, p. 84). Si bien lo político abarcaba un campo más amplio de socialización, sin duda, el tirar piedras era una poderosa y masiva forma de expresión política callejera. También era una forma de defensa, aunque poco podían hacer contra los pertrechos de los carabineros y las fuerzas armadas que irrumpían cotidianamente en sus territorios. Escuchemos a Gabriel:

Son peleas bastante desequilibradas, apenas se logra retenerlos un poco en base a piedras, unas molotov o lo que se tenga a mano. Una vez estábamos en un lugar público y llegó una cuca... el cura les pidió que no se exaltaran y dieron la oportunidad de que se acabara el acto al tiro sin que ellos hicieran nada. Nosotros aceptamos, echamos a toda la gente a sus casas, a todos los viejitos, y nos quedamos unos 40 cabros que queríamos pelear. Nos agarramos como tres horas. Andábamos todos con hondas (Politzer, 1988, p. 44).
La defensa de los territorios, de sus calles y de su gente, también era un imperativo para jóvenes como Juan, que recuerda con detalle cuando carabineros golpeó al reconocido sacerdote de su población, Pierre Dubois:

Como a la quinta protesta ya no los dejamos entrar más ¡Si quebraban todos los vidrios!... Si hasta al padre Pierre le pegaron. El padre se puso al medio de la calle para que no entraran a la población y le tiraron la micro encima. Él se quedó parado no más y tuvieron que frenar, entonces se bajaron dos pacos y le mandaron un combo. -Loco, le están pegando al padre!-gritamos. Y partimos todos cargados de piedras (Politzer, 1988, p. 68).

Las piedras lanzadas contra los vehículos de la policía y contra sus tripulantes eran temidas por el cuerpo de carabineros que incluso sofisticó su atuendo para protegerse de esa lluvia que los buscaba como blanco predilecto. Claro que con piedras era difícil ganarle la batalla al dispositivo represivo, pero al menos lograban contenerlos por un tiempo y, lo fundamental, lograban ser un medio para manifestar el repudio y disparar los agravios contenidos. Raúl Canales presenció varias de esas trifulcas en la población La Pintana:

Aquí pasaba un furgón de pacos por Lo Martínez, que es por donde se transitaba, y llegaba abollado cuando llegaba a Santa Rosa. ¡Lo apedreaban desde que salía hasta allá afuera, y después para entrar, lo mismo!... en la noche en que estaba como todo calladito, de repente se sentía el motor de un vehículo y jla sonajera de latas! No podían pasar los pacos, los cabros se apostaban ahí en las esquinas pa' darle, apedreaban lo que pasara en realidad, no solamente a los pacos. La rabia, la impotencia de no sé, de escuchar, que te contaron, que la radio dijo lo que estaba pasando en otros lados, cuántos murieron, a cuántos balearon, cuántos presos hay, todas esas cosas hacían que acumularas mucha rabia y una forma de enfrentarte a eso y desahogar tu cuento era esto, estar ahí, tirar piedras, no tenerle miedo a la cosa, y yo creo que eso es lo que pasó acá (Raúl Canales, 7 julio 2010). 
Entre los jóvenes que se apostaban en las calles poblacionales, encontramos a Pedro, cargado como él señala: "con hondas, algunas molotov huachas y harta piedra". De eso se enorgullece: "Siempre tuvimos buenos encuentros con los pacos. Primero los agarrábamos a piedrazos, después corríamos de a tres y le tirábamos una molotov" (Politzer, 1988, p. 84). La distancia para "agarrarlos a camotazo limpio" no puede ser mucha, es necesario acercarse, exponerse. Unos se adelantan, otros retroceden, los más chicos buscan provisiones de piedras en tanto van observando y aprendiendo. En medio de ese caos hay un orden que sus protagonistas conocen. Es la organización de la calle, espontánea, no por irracional sino por directa, sin mediaciones.

\section{Las calles}

Las Jornadas de Protesta fueron un hecho sociopolítico significativo que logró cambiar la fisonomía de la ciudad. Con ellas, o dentro de ellas, los movimientos, los sentidos, la ocupación de los espacios fueron otros. Un nuevo sentido emergió del conjunto de sus prácticas transformadoras. Se trató de actores, pasos y preocupaciones particulares, articulados en significados, trayectorias y repertorios colectivos, políticos. Dichas prácticas nacieron en confrontación con el poder y el orden manifiesto en la ciudad. Ante una señal previamente convenida, rompían el monólogo estatal, el sentido del tránsito y el funcionamiento de sus recorridos. Tal como hemos reseñado, hablaron con el ruido, el fuego, las piedras, hablaron multiplicando las posibilidades de asignación de sentido y significado de la política.
Las historias que aquí nos convocaron fueron callejeras y hechas a mano. Fueron una forma de vivir, resistir y construir el espacio público. También una forma de comunicar. Porque el acto de caminar, marchar, escabullirse o congregarse es al sistema urbano lo que la enunciación es a la lengua. Tanto el estilo (tratamiento singular de lo simbólico), como el uso (tratamiento de un código) apuntan a una "manera de hacer". El protestar en la ciudad conforma trayectorias y repliegues que no cesan de alterarla, selecciona atajos, crea rodeos. Los pasos también rompen y construyen fronteras, en relación con su posición en el enfrentamiento callejero constituyen un cerca y un lejos, un aquí y un allá, un nosotros y un ellos.

Por eso es que la Primera Jornada Nacional de Protesta fue impresionante para sus protagonistas y sus observadores, más para quienes solo recordaban en forma borrosa las concentraciones de "antaño", como Gabriel, que a pesar de realizar pequeñas acciones audaces durante los años anteriores, a pesar de considerarse en estado de "rebelión permanente", de imprimir y distribuir panfletos, hacer rayados o participar en protestas fugaces, era solo un niño cuando los militares irrumpieron en 1973 en la vida cotidiana:

La primera protesta nos dejó impresionados, superó todas las expectativas: todo el mundo estaba en las calles. La cosa nos quedó grande, no hicimos nada, ni barricadas ni nada. Los pacos tampoco se lo esperaban, porque ni se asomaron. Toda la gente salió a la calle a tocar las ollas. Todo el mundo estaba contento, parecía carnaval, saltaban, hueviaban, tocaban guitarra, cualquier locura, parecía como que Chile hubiera ganado el mundial de fútbol. ¡Es una de las cuestiones más encachadas que me ha tocado vivir! (Politzer, 1988, p. 47). 
En las poblaciones periféricas, la relación era fuerte entre el territorio y la protesta. Más que "en los márgenes" de la segmentación, el protestar de los pobladores se ubicaba en los intersticios. Desde ahí interpelaba a los poderosos para desmantelar sus designios y romper las continuidades de su tiempo, con sus voces y nombres propios. Significaba tomarse los lugares y los relojes, los pasajes y esos inmensos terrenos baldíos y polvorientos tan comunes de aquella época, destinados a áreas verdes y juegos infantiles, cansados de esperar otro futuro que no llegaba, igual que esa generación de jóvenes en dictadura. Así nos señala Claudio:

La protesta estaba asociada a esa cosa de diversión, de pelea, de combate, de rechazo hacia la dictadura, pero también de querer ocupar los espacios que no podías ocupar en un día normal, significaba una mínima apropiación de espacio y de poder. La gente salía a manifestarse porque no había pacos ni complot ni ninguna hueá. Ahí estaba la calle para jugar a la pelota, para tirar piedras, cagarte de la risa. Esos eran los espacios de sociabilidad. $Y$ a medida que pasaba el tiempo, los que estábamos más metidos con colores políticos nos fuimos identificando con ciertas ideas básicas que aparecen en las protestas, las consignas, los colores, los volantes, los instructivos de cómo se hace una barricada, los discursos que aparecían, los saqueos (Claudio Pérez, 28 septiembre 2010).

Después del primer reconocimiento colectivo en esos espacios que eran sus espacios vino la delimitación, la defensa y la presencia en la escena y la discusión pública. Aparecieron ellos, protestando desde su lugar, desde sus calles, en la puerta de sus casas. Si pensamos que era algo nuevo, nos equivocamos. En efecto, en diversas coyunturas políticas del conmocionado siglo $\mathrm{XX}$ chileno, las llamadas "huestes de la periferia" irrumpieron en el centro político-administrativo exigiendo a los burócratas oír sus reclamos y demandas de justicia, pero también lo hicieron desde sus territorios, levantando barricadas, haciendo sabotajes en la línea férrea o desquitándose ante el alza del costo de la vida en los terminales de transporte público contra las maquinarias y las garitas. Así sucedió, por ejemplo, en la llamada Rebelión de la Chaucha de agosto de 1949 o en la rebelión popular ocurrida en la población José María Caro en noviembre de 1962.

Foto 4. Población Los Copihues, julio 1986.

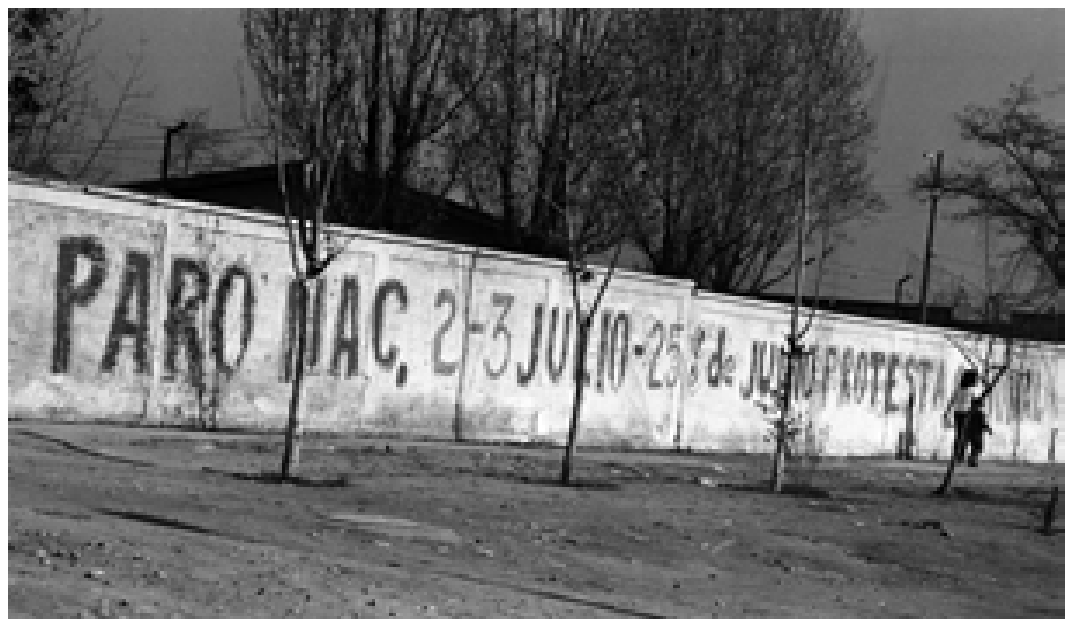

Archivo Documental Vicaría de la Solidaridad. 
Sin duda, las calles y sus muros fueron utilizados como un masivo medio de comunicación social. Rayados y afiches pegados en paredes, panfletos arrojados al pavimento, convocaban a la protesta, al paro, a la marcha. Se burlaban del poder, maldecían, prometían vientos redentores. Los panfletos fueron lanzados en avenidas y esquinas claves para ser recogidos y leídos. Los muros fueron rayados para ser vistos. El momento, la hora, el espacio; el ritmo y la energía, todo eso confluía. Se escogen ciertas calles, se rechazan otras. Unas tienen nombres propios, otras fechas, algunas no tienen firma, pero todas se jerarquizan y conforman trayectorias según su capacidad para significar. En las calles quedaron las marcas donde cayeron los muertos, las rutas fúnebres al cementerio, las flores y los homenajes con que hombres y mujeres despidieron a sus compañeros y compañeras. Esa experiencia y construcción del espacio público ni se borra ni desaparece. Se trata de una herencia inmaterial (formas de estar juntos y construir un colectivo) transmitida de generación en generación, que subyace bajo las ocupaciones cotidianas de la ciudad y que se activa en momentos en que destellan nuevas experiencias rebeldes que cuestionan la toponimia y las memorias oficiales, sus órdenes y ordenamientos.

\section{Reflexión final}

La protesta popular es un campo múltiple de fuerzas, de participación y socialización política que nos permite interiorizarnos en las tensiones y los conflictos que remueven a una sociedad. Es por ello que su análisis es sumamente fértil para la investigación social. En estas páginas hemos recorrido un tiempo privilegiado para indagar en lo que fue la lucha contra la dictadura entre los años 1983-1986, cuando la oposición movilizada logró conformar ese momento que Tomás Moulian (1997) catalogó como "el acoso", es decir, una correlación de fuerzas favorable para terminar con la dictadura sin negociar con el régimen. Fue un momento privilegiado de desarrollo de la protesta popular que habló con un lenguaje espeso que planteaba opciones distintas a las que finalmente encauzaron nuestra transición a la democracia.

Sin duda significaron enormes costos para los sectores que las protagonizaron, en especial las clases populares. Dado el espacio y la opción de análisis, no nos hemos detenido en ello, pero debemos ser conscientes de que estos actos rebeldes eran castigados y enfrentados con todo el dispositivo de los aparatos represivos del Estado, en un clima de absoluta impunidad. Aun así, fueron cientos de miles quienes estuvieron dispuestos a rebelarse y pagar los costos. ¿Qué querían expresar a través de esa persistencia y las diversas formas de lucha que están presentes en la disputa callejera?

Si sabemos escuchar los mensajes de la protesta durante esos días con sus noches, si sabemos leer los mensajes de los sonidos y las piedras, del fuego y de los muros, comprenderemos que los costos de la instauración del modelo neoliberal lo pagaron los sectores más desposeídos, con años de cesantía, hambre, humillaciones físicas y psíquicas indescriptibles, y que el autoritarismo y la opresión política era asfixiante. Sabremos de la activación de una experiencia pretérita de lucha. Pero, por sobre todo, que una sociedad, que se reconocía colectivamente y se organizaba, se atrevió a decir: "Nosotros, hasta aquí aguantamos". 


\section{Notas}

${ }_{1}^{1}$ Declaración de Principios del Gobierno Militar, 11 de marzo 1974. Recuperado de http://www.archivochile.com/Dictadura_militar/html/ dic_militar_doc_junta.html

${ }^{2}$ Sobre los aparatos represivos y crímenes de Estado en Chile, ver el Informe de la Comisión Nacional de Verdad y Reconciliación (Informe Rettig) (Comisión Nacional de Verdad y Reconciliación, 2010) y el Informe de la Comisión Nacional sobre Política y Tortura (Informe Valech) (Comisión Nacional sobre Política y Tortura, 1991).

${ }^{3}$ El toque de queda fue una disposición que prohibía salir de las casas y/o transitar en el espacio público a partir de cierta hora estipulada por los militares, generalmente después de las 24 horas $\mathrm{o}$ incluso antes.

${ }^{4}$ Comunicado Público, Confederación de Trabajadores del Cobre, Santiago, abril o mayo de 1983, Archivo Documental Vicaría de la Solidaridad. Entre las indicaciones: 1. No enviar a nuestros hijos al colegio; 2. No comprar absolutamente nada; 3 . A las 8 de la noche golpear las cacerolas en las casas; 4 . Los vehículos circulando en las ciudades deben hacerlo en forma lenta. A no más de $30 \mathrm{~km}$ por

\section{Referencias bibliográficas}

Arriagada, G. (1998). Por la razón o la fuerza: Chile bajo Pinochet. Santiago: Editorial Sudamericana.

Benjamin, W. (2005). Tesis sobre la historia y otros fragmentos. México: Contrahistorias.

Bravo, V. (2012). Neoliberalismo, protesta popular y transición en Chile, 1973-1989. Política y Cultura, (37), 85-112. Recuperado de http://www.scielo.org.mx/pdf/polcul/n37/n37a5.pdf

(2016). Iglesia liberadora, rearticulación de la política y protesta social en Chile (1973-1989)". Historia Crítica, (62), 77-96. Recuperado de https://histcrit.uniandes.edu.co/index.php/es/revista-no-62

(2017). Piedras, barricadas y cacerolas: las Jornadas Nacionales de Protesta, Chile 1983-1986. Santiago: Universidad Alberto Hurtado.

De Certeau, M. (1996). La invención de lo cotidiano. Vol. 1. Artes de hacer. México: Universidad Iberoamericana.

Delamaza, G. \& Garcés, M. (1985). La explosión de las mayorías: Protesta Nacional 1983-1984. Santiago: ECO.

Fillieule, O. \& Tartakowsky, D. (2015). La manifestación, cuando la acción colectiva toma las calles. Buenos Aires: Siglo XXI.

Foxley, A. (1988). Experimentos neoliberales en América Latina. México: Fondo de Cultura Económica.

Gárate, M. (2012). La revolución capitalista de Chile (1973-2003). Santiago: Universidad Alberto Hurtado.

Comisión Nacional de Prisión Política y Tortura (2010). Informe Comisión Nacional de Prisión Política y Tortura (Comisión Valech), Santiago de Chile. Recuperado de http://www.derechoshumanos. hora; 5. No haciendo trámites en las oficinas públicas o privadas; 6. Apagar las luces y todos los artefactos eléctricos en las casas y edificios a las 9:30 de la noche en punto, durante 5 minutos. En los días consecutivos, fueron emitidos otros instructivos para el "Día de la Gran Protesta Nacional" que agregaron otras propuestas dirigidas hacia cada sector, por ejemplo, a los trabajadores: Paralizando faenas por algunas horas; Trabajo lento; No asistiendo al comedor a las horas de almuerzo; Realizando asambleas que discutan el llamado de la CTC y la realidad de su propio sindicato y empresa; Declarando públicamente su adhesión a la protesta.

${ }^{5}$ Las cifras de detenciones señalan que, si en 1982 se registraron 1.789 detenciones, en 1983, año en que estallaron las Jornadas Nacionales de Protesta, se incrementaron a 15.077, para aumentar a más del doble en 1984, con el registro de 39.440. Y si en 1985 disminuyen a 8.946, volvieron a aumentar en 1986, el llamado "año decisivo", con 33.665 apresamientos.

${ }^{6}$ Un análisis crítico de los argumentos y la función de los "teóricos de la transición" en Salazar (2006).
net/paises/America/derechos-humanos-Chile/informes-comisiones/ comision-nacional-prision-politica-y-tortura.htm

Comisión Verdad y Reconciliación (1991). Informe de la Comisión Verdad y Reconciliación (Informe Rettig), Santiago de Chile. Recuperado de http://www.cverdad.org.pe/ifinal/index.php

Meller, P. (1996). Un siglo de economía política chilena: 1890-1990. Santiago: Andrés Bello.

Montero, C. (1997). La revolución empresarial chilena. Santiago: Corporación de Estudios para Latinoamérica, Dolmen.

Moulian, T. (1997). Chile actual: anatomía de un mito. Santiago: LOM.

Pavilack, J. (2011). Mining for the Nation: The Politics of Chile's Coal Communities from the Popular front to the Cold War. Pennsylvania: University Park, The Pennsylvania State University.

Politzer, P. (1988). La ira de Pedro y los otros. Santiago: Planeta.

Ramón, A. de (2007). Santiago de Chile: historia de una sociedad urbana. Santiago: Catalonia.

Salazar, G. (2006). La violencia política popular en las "Grandes Alamedas": la violencia en Chile 1947-1987 (una perspectiva histórico popular). Santiago: LOM.

Thompson, E. P. (1997). Historia social y antropología. México: Instituto Mora.

Tilly, Ch. (2008). Contentious Performances. Cambridge: Cambridge University Press.

Tironi, E. (1987). Marginalidad, movimientos sociales y democracia. Proposiciones, (14), 9-20.

Valenzuela, E. (1984). La rebelión de los jóvenes (un estudio de anomia social). Santiago: Sur. 